\title{
POSTOPERATIVE SEQUELAE OF RADICULAR CYST ENUCLEATION USING PIEZOSURGERY VERSUS CONVENTIONAL TREATMENT MODALITY
}

Abdel Monem Tawfik*, Mohamed Zaghlool Amer** and Ibrahim Almabrouk Aql ${ }^{* * *}$

\begin{abstract}
Problem statement: The need to develop an alternative surgical tools facilitates cyst enucleation with minimal recurrence risk has introduced piezosurgery as a recent treatment modality for enucleation of radicular cyst especially, when cyst remnants are localized in inaccessible area. So, this study was based to assess postoperative sequelae of radicular cyst enucleation using ultrasonic bone surgery (piezosurgery) in comparison with conventional surgical treatment modality.
\end{abstract}

Patients and Methods: Twenty patients were randomly divided into two equal groups for treatment of radicular cystic lesion of size ranged between $2-4 \mathrm{~cm}$. Ten Patients included within $1^{\text {st }}$ group were subjected to surgical enucleation of cystic lesion with classical application of conventional rotary instruments. While, ten patients included within $2^{\text {nd }}$ group were subjected to surgical enucleation of cystic lesion with application of piezosurgery. All patients were evaluated intraoperatively in terms of bleeding either at 24 hours and 7 days. Pain and swelling were assessed after 2 and 7 days. Bone mineral density was recorded immediately, 6 and 12 months.

Results: No statistical significant difference was recorded between both groups regarding to severity of intra-operative bleeding and pain severity after 2 days ( $\mathrm{P}=0.068-0.111$ respectively). A statistical significant difference was recorded between both groups regarding to summation of swelling and BMD after 2 days of follow up ( $\mathrm{P}=.001-0.015$ respectively). Additionally, a statistical significant difference was recorded between both groups regarding to inter-incisal distance (IID) after 24 hours and 2 days $(\mathrm{P}=0.002$ - 0.035 respectively) and time of surgery $(\mathrm{P}=0.013)$.

Conclusion: Although, piezosurgery can be represented as technique sensitive maneuver affected seriously by several factors either related to operator experience or device adoption by itself. However, the collective findings of this study declared their positive impact on reducing the postoperative sequelae of radicular cyst enucleation compared with conventional treatment modality.

* Professor of Oral \& Maxillofacial Surgery, Faculty of Dentistry, Mansoura University.

** Associate Professor of Oral \& Maxillofacial Surgery, Faculty of Dentistry, Mansoura University.

*** B.D.S, Tripoli university, Colleague Of Master Degree Faculty Of Dentistry, Mansoura University 


\section{INTRODUCTION}

Radicular cyst is the most common of all jaw cysts and consists of about $52 \%$ to $68 \%$ of all cysts affecting the human jaws. Additionally, it ranged from $6 \%$ to $57.69 \%$ of all periapical lesions. ${ }^{(1,2,3)}$ Most typical of the radicular cyst is without symptoms and detected when periapical radiographs are taken of teeth with non-vital pulps. Patient sometimes complains of slowly enlarging swellings. ${ }^{(4)}$

The alternatives of treatment for radicular cyst can be conventionally treated by nonsurgical root canal therapy when lesion is confined to a small area or with surgical treatment procedures including enucleation, marsupialization or decompression when lesion is large. ${ }^{(5)}$ The use of hand tools and surgical burs to elevate the cyst epithelium and the occurrence of bleeding have seen to be of negative surgical effect in terms of complications and recurrence. ${ }^{(6)}$

The extension of epithelial cyst tissues usually directs to the interdental septa of neighboring teeth. In these areas, the cyst epithelium becomes thinner, making it difficult to wholly enucleate the cyst without leaving any content behind. Furthermore, enucleation become more difficult and take more time as a result of manipulation problems and the need to protect adjacent anatomic structures. ${ }^{(7)}$

Additionally, conventional rotary instruments have shown an increase of risk for incapacity to control the instruments because of deficient experience of the surgeon and unexpected operator error that may also result in damage to important vital anatomic structures (nerves, maxillary sinus, and nasal mucosa) in the surrounding area of the surgical site.

In 2001, Vercelotti et al. developed ultrasonic bone surgery for clinical practice use. ${ }^{(8)}$ One of the significant advantages of piezosurgery is minimizing hemorrhage as a result of the cavitations effect created by microvibration, keeping the field of view as wide as possible and allowing cystic remnants in the operation site to be easily detected and excised. Additionally, the piezosurgery device's angular and straight tips can facilitate manipulation, principally in interdental areas, becomes more easier to right the entry of surgical operation site and avoid majority of cystic epithelium perforation during enucleation. ${ }^{(9)}$

So, this study was based to assess postoperative sequelae of radicular cyst enucleation concerning to pain, swelling, trismus and bleeding using ultrasonic bone surgery (piezosurgery) in comparison with conventional surgical treatment modality.

\section{PATIENTS AND METHODS}

Twenty patients selected from department of Oral and Maxillofacial Surgery of Mansoura University with radicular cystic lesion ranged between $2-4 \mathrm{~cm}$. The apical root canal had $6 \mathrm{~mm}$ or more without the presence of a post. Periradicular surgery was carried out only in the absence of acute symptoms. Patients did not have general medical contraindications for oral surgical procedures. Teeth with pathoses associated with vertical root fracture and perforation of lateral canal walls were excluded from this study. Additionally, teeth with traumatic injuries and severe periodontal bone loss were excluded (5 $\mathrm{mm}$ probing depth).

\section{Piezosurgery System}

The piezoelectric device (Ultra Surgery_ Manufacture by Guilin Woodpecker Medicl Instrument Co. China.) was adjusted of ultrasonic vibrations at a frequency ranged from 24.0 to $29.5(\mathrm{kHz})$, oscillation (amplitude) 60 to 210 micrometers $(\mu \mathrm{m})$ and power less than 80 Watts (W),with minimal manual pressure for precise bone cutting which allows selective cutting only in mineralized structures without damaging vital soft tissue, and less surgical trauma during osteotomy. ${ }^{\mathbf{1 0 - 1 6}}$ 


\section{Patients Grouping}

All patients were randomly divided into two equal groups for treatment of radicular cystic lesion. Ten Patients included within $1^{\text {st }}$ group were subjected to surgical enucleation of cystic lesion with classical application of conventional rotary instruments. While, ten patients included within $2^{\text {nd }}$ group were subjected to surgical enucleation of cystic lesion with application of piezosurgery (UltraSurgery_Manufacture by Guilin WoodPecker Medical Instrument Co.CHINA).

Patients within these two groups were subjected to clinical and radiographic examination. Fine needle aspiration biopsies and cytological evaluation were conducted before surgery.

\section{Surgical Procedures}

Surgical procedures were performed under local anesthesia Mepivacaine HCL 2\% 1-20.000 (Manufacture by Alexandria Co. for pharmaceutical- Alexandria- Egypt). Following prophylactic antibiotic preparations, a full thickness mucoperiostial flap was elevated with enough access into surgical area. In the conventional group, the cyst cavity was accessed by using both of rounded and fissure burs with adequate cooling system. Cyst epithelium lining was elevated and

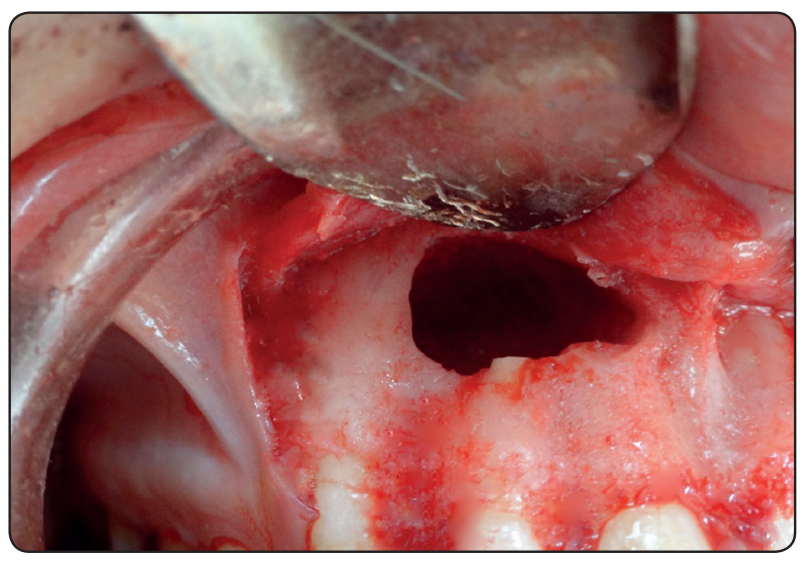

Fig. (1) A photograph showing the created osseous window followed with cyst enucleation and apicectomy procedures using conventional drills. apicectomy procedures were performed by using fissure burs (Fig. 1). While, in the piezosurgery group, osteotomies were performed by using both of piezosurgery device of variable frequencies and scalpel osteotomy tips. In this study, piezosurgery device's scalpel osteotomy tip UL3 was used for treatment the cystic cavity through designed, open window and removal of vestibular compact bone. Also, aided to detach the membrane of cystic lesion, and poor prognosis teeth were extracted. The beginning of the cyst epithelium was enucleated from the apical aspect of the cyst, by using the perpendicular and wide-angle spatula tips designed for use in sinus elevationUL3, UL1, UL5.

In cases which require apicectomy through cutting the apices of teeth by using piezosurgery, an extra apparatus tip US1 was used. After removing all of the cyst epithelium, the spatula tipsUL1, UL5 were used again to clean the cyst cavity, and the epithelial residue was removed outside the surgical field (Fig. 2).

In both groups following bleeding control, surgical wounds wereclosed primarily with (3.0 Silk). All patients were maintained on antibiotics therapy consisted of amoxicillin and Clavulanate potassium (Augmentin, Medical Union Pharmaceuticals. Cairo, Egypt) that was administered in dose $1 \mathrm{gm}$

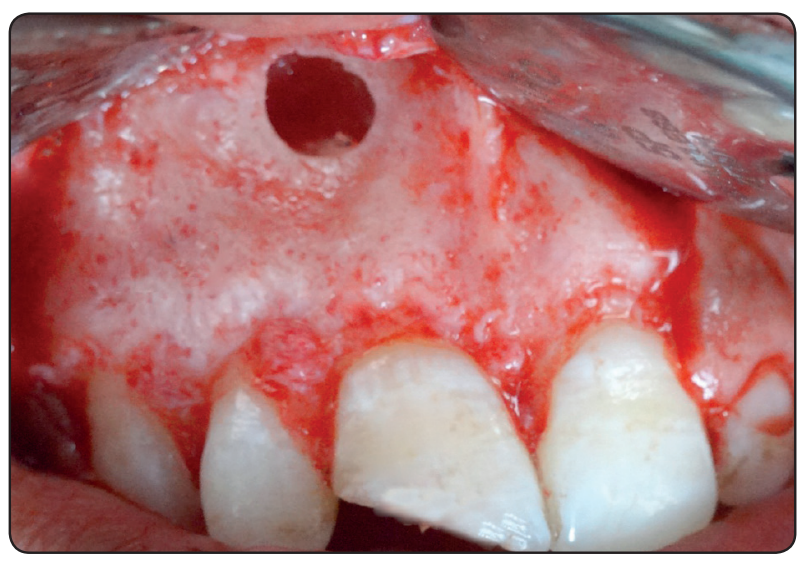

Fig. (2) A photograph showing the created osseous window followed with cyst enucleation and apicectomy procedures using piezosurgery. 
every 12 hour, starting from 30 minutes before intervention, and continued for 4-5days during the post-operative period, accompanied by nonsteroidal anti-inflammatory drugs Ibuprofen 600 (BRUFEN_ produced by : khirapharm. and Chem. Ind. Co. Cairo-Egypt) three times per day.

Additionally, antiseptic mouth wash chlorhexidine (Oraldene _ Produced by Hikma Pharma S.A.E.. $6^{\text {th }}$ of October City - Egypt) was used for 7 days after surgery in order to reduce the bacterial local load and to avoid any possible postsurgical infection.

\section{Clinical Evaluation}

All patients were evaluated intra-operatively in terms of bleeding, ease of manipulation, length of operation time. All patients included in this study were assessed postoperatively regarding to the following parameters:

\section{I-Bleeding}

The bleeding were assessed intaoperatively and postoperatively after 24 hours and 7 days using bleeding scale. ${ }^{17}$ Grade 0 indicates very low (almost no bleeding). Grade 1 indicates low (slight oozing of blood from the surgical site which usually stopped by itself after pressure application). Grade 2 indicates normal (clinical significant). Grade 3 indicates high (bleeding occurred after clot significantly formed). Grade 4 indicates very high (excessive bleeding that could not be controlled by local hemostatic agent).

\section{II-Pain}

Pain was evaluated using Visual Analogue Scale (VAS) at $2^{\text {nd }}$ and $7^{\text {th }}$ postoperative days. For this purpose the patient was then asked to subjectively rate the intensity of pain on a brightness-coded color scale with the endpoints "no pain" and "very severe pain". For evaluating the patient's assessment, the examiner disposed a scale ranging from 1 to 100 on the backside being assigned to the different brightness levels on the front side of the scale. ${ }^{18}$

\section{Assessment of facial swelling}

The facial swelling was determined by measuring the distance from the corner of the mouth to the tragus and from the lateral canthus of the eye to the angle of the mandible. The sum of these measurements was recorded as the facial size before the surgery. Then assessment was done at $2^{\text {nd }}$ day and $7^{\text {th }}$ day postoperatively. ${ }^{19}$

\section{Trismus assessment}

The presence of trismus was analyzed through measuring the interincisal distance (IID). Mouth opening was measured from upper central to lower central incisor edge during the maximum mouth opening before the surgical procedures and evaluated at 24 hours, 48 hours and 7 days postsurgically. ${ }^{20}$

\section{Radiographic assessment of bone mineral den- sity (BMD)}

Radiographic assessment preoperatively, immediately, 6, and 12 months postoperatively was performed using Digital panoramic radiograph DPR. Before the optical analysis of gray level all the radiographic films and the corresponding images were scanned then filed in a computer in tiff format (tagged image file format). Additionally, all of the scanned images were processed with the Adobe Photoshop Elements 2.0 software. ${ }^{21}$ To compare them with the same patients radiographs which were taken at different times, contrast matching was performed.

The differences between the radiographic films is the tooth itself that was used as reference. The control region (tooth) and the regions of interest (cyst cavities) then defined through a gray scale of 255 tonalities using gray-level histograms. A single examiner was demarcate the outline of the lesion. The control regions from radiographs taken at different times were matched, and the mean gray-level values of the regions of interests then calculated and compared with each other. ${ }^{22}$ 


\section{Statistical Analysis}

Statistical analysis of data was done by using excel program for figures and SPSS (SPSS, Inc., Chicago, IL). program statistical package for social science. The description of the data was done in form of mean (+/-) SD for quantitative data. Frequency $\&$ proportion for qualitative data. The analysis of the data was done to test statistical significant difference between groups. For quantitative date Independent sample t-test then was used to compare between two groups. Chi square test was used for qualitative data. $\mathrm{P}$ is significant if $<$ or $=0.05$ at confidence interval $95 \%$.

\section{RESULTS}

This study was conducted over twenty patients of radicular cyst that fullfil the inclusion criteria and devided into two equal groups, $1^{\text {st }}$ group (conventional group) and $2^{\text {nd }}$ group (piezosurgery group) according to the surgical method of cyst removal. All patients included in this study were evaluted postoperatively regarding to the following parameters.

\section{Bleeding assessment}

The bleeding was assessed intraoperatively and postoperatively after 24 hours and 7 days.

\section{Intraoperative bleeding}

Bleeding grades distribution within patients consisting both groups were illustrated in (Table1). No statistical significant difference was recorded between both groups regarding to severity of intraoperative bleeding $(\mathrm{P}=0.068)$ (Table 1).

\section{Postoperative bleeding}

All patients were assessd postoperatively regarding to bleeding severity after 24 hours and 7 days. Firstly, after 24 hours in control group, seven patients showed no bleeding grade and three patients revealed mild grade. On the other hand, eigth patients in study group showed no bleeding and two patients recorded mild grade of bleeding. Furthermore, no patients in both groups showed moderate grade of bleeding. Finally, in both groups after 7 days all patients showed no bleeding. No statistical significant difference was recorded between both groups regarding to severity of postoperative bleeding after 24 hours $(\mathrm{P}=0.606)$.

TABLE (1) Showing distribution of intraoperative bleeding severity among patients included within both groups and level of significance.

\begin{tabular}{|c|c|c|c|c|c|}
\hline \multirow{2}{*}{$\begin{array}{c}\text { Group/Bleeding } \\
\text { grades }\end{array}$} & \multicolumn{2}{|c|}{$\begin{array}{c}\text { Control group } \\
(\mathrm{n}=10)\end{array}$} & \multicolumn{2}{|c|}{$\begin{array}{c}\text { Study group } \\
(\mathrm{n}=10)\end{array}$} & \multirow{2}{*}{ P-value } \\
\cline { 2 - 5 } & No & $\%$ & No & $\%$ & \\
\hline No & 0 & 0 & 0 & 0 & \multirow{2}{*}{.068} \\
\hline Mild & 4 & 40 & 8 & 80 & \multirow{2}{*}{0} \\
\hline Moderate & 6 & 60 & 2 & 20 & \multirow{2}{*}{0} \\
\hline Sever & 0 & 0 & 0 & 0 & \\
\hline
\end{tabular}

\section{Pain assessment}

Regarding to postopertive pain recorded at the $2^{\text {nd }}$ day according to VAS, four patients in control group were sufferd from mild pain, six patients sufferd from moderate pain. On the other hand, in study group two patients showed no pain, six patients sufferd from mild pain, two patients suffered from moderate pain. After seven days, all patients of both groups showed no pain. No statistical significant difference was recorded between both groups regarding to pain severity after 2 days $(\mathrm{P}=0.111)$.

\section{Swelling assessment}

\section{Preoperative assessment}

Preoperative mean and standard deviation of three points used for swelling assessment among patients included within both groups were illustrated in (Table 2). No statistical significant 
differences were recorded between both groups regarding to preoperative assessment of three points used for detection of swelling $(\mathrm{P}=0.277,0.94,1.00)$ respectively (Table 2 ).

\section{Postoperative assessment}

In control group, point A was recorded with an average mean $(9.65 \pm 1.348)$ at $2^{\text {nd }}$ day comapered with an average mean $(8.65 \pm 1.124)$ after 7 days while, in study group, point A showed an average mean $(8.36 \pm 0.83)$ after 2 days comapered with an average mean $(7.95 \pm 0.735)$ after 7 days. In control group, point B showed an average mean $(12.59 \pm 0.467)$ after 2 days comapered with an average mean (11.74 \pm 0.609$)$ after 7 days. However, in study group, point B showed an average mean (11.640 \pm 0.68$)$ after 2 days comapered with an average mean (10.28 \pm 0.56$)$ after 7 days. Moreover, in control group, point $\mathrm{C}$ showed an average mean (14.137 \pm 0.547$)$ after 2 days comapered with an average mean $(14.14 \pm 0.832)$ after 7 days. However, in study group, point $\mathrm{C}$ showed an average mean (14.14 \pm 0.615$)$ after 2 days comapered with an average mean $(14.30 \pm 0.692)$ after 7 days. No statistical significant differences were recorded between both groups regarding to severity of postoperative swelling after $2^{\text {nd }}$ day at line $\mathrm{A}$ and $\mathrm{C}$ $(\mathrm{P}=0.39,0.682)$ while, a significant difference was recorded at line $\mathrm{B}(\mathrm{P}=0.001)$.

No statistical significant differences were recorded between both groups regarding to severity of postoperative swelling after 7days regarding to line $\mathrm{A}$ and $\mathrm{C}(\mathrm{P}=0.39,0.181)$ respectively. However, a statistical significant difference regarding to line $\mathrm{B}$ was recorded $(\mathrm{P}=.001)$.

Comparative assessment between preoperative and postoperative mean and standard deviation of three points used for swelling assessment after 2 and 7days among patients included within both groups and level of significance were illustrated in (Table 3).

\section{Summation of swelling}

Preoperatively summation of swelling showed an avarge mean in control group (33.36 \pm 1.218$)$, while in study group the avarege mean was $(37.73 \pm 1.99)$. No statistical significant difference was recorded when comparing both groups preoperatively regarding to summation of swelling $(\mathrm{P}=.065)$ (Table 4).

Postoperatively, summation of swelling at $2^{\text {nd }}$ day showed an avarge mean of control group $(35.08 \pm 1.058)$, while in study group the avarege mean was $(32.650 \pm 1.55)$. A statistical significant difference was recorded between both groups for same time interval of follow up ( $\mathrm{P}=.001)$ (Table 4). Moreover, summation of swelling at $7^{\text {th }}$ day showed an avarge mean in control group $(33.88 \pm 0.758)$, while, in study group the avarege mean was (34.53 \pm 0.947$)$. No statistical significant difference was recorded between both groups for same time interval of follow up $(\mathrm{P}=0.231)$ (Table 4).

In both groups, a statistical significant differences were recorded when comparing these values recorded preoperatively versus those recorded either at $2^{\text {nd }}$ or $7^{\text {th }}$ day postoperatively $(\mathrm{P}=0.002$ 0.001) ( $\mathrm{P}=0.004-0.001)$ respectively. Additionally, in both groups, no statistical significant differences were recorded when comparing these values recorded after 2 days versus those recorded after 7 days postoperatively $(\mathrm{P}=.138-0.195$ respectively).

TABLE (2) Showing preoperative mean and standard deviation of three points used for swelling assessment among patients included within both groups and level of significance.

\begin{tabular}{|c|c|c|c|}
\hline $\begin{array}{c}\text { Swelling } \\
\text { line/Group }\end{array}$ & $\begin{array}{c}\text { Control } \\
\text { group }(\mathrm{n}=10)\end{array}$ & $\begin{array}{c}\text { Study group } \\
(\mathrm{n}=10)\end{array}$ & $\mathrm{p}$-value \\
\hline Line A & $8.65 \pm 1.124$ & $8.31 \pm 0.827$ & $\mathrm{p}=0.277^{*}$ \\
\hline Line B & $10.89 \pm 0.632$ & $10.20 \pm 1.00$ & $\mathrm{P}=0.94^{*}$ \\
\hline Line C & $13.79 \pm 0.535$ & $14.44 \pm 0.771$ & $\mathrm{p}=1.00^{*}$ \\
\hline
\end{tabular}


TABLE (3) Showing comparison between preoperative and postoperative mean and standard deviation of three points used for swelling assessment after 2 and 7days among patients included within both groups and level of significance.

\begin{tabular}{|c|c|c|c|c|c|c|}
\hline \multirow{2}{*}{$\begin{array}{c}\text { Swelling lines/ } \\
\text { Days }\end{array}$} & \multicolumn{3}{|c|}{ Control group (n=10) } & \multicolumn{3}{c|}{ Study group (n=10) } \\
\cline { 2 - 8 } & Line A & Line B & Line C & Line A & Line B & Line C \\
\hline Pre & $8.65 \pm 1.124$ & $10.89 \pm 0.632$ & $13.79 \pm 0.535$ & $8.31 \pm 0.827$ & $10.20 \pm 1.00$ & $14.44 \pm 0.771$ \\
\hline $2^{\text {nd }}$ & $8.36 \pm 0.83$ & $12.59 \pm 0.4677$ & $14.137 \pm 0.547$ & $9.65 \pm 1.348$ & $12.640 \pm 0.68$ & $14.14 \pm 0.615$ \\
\hline $7^{\text {th }}$ & $8.00 \pm .2641$ & $11.74 \pm 0.609$ & $14.14 \pm 0.832$ & $8.95 \pm 0.735$ & $12.28 \pm 0.56$ & $14.30 \pm 0.692$ \\
\hline$p^{*}$-value & $\mathrm{P} 1=.000$ & $\mathrm{P} 1=.000^{*}$ & $\mathrm{P} 1=.517$ & $\mathrm{P} 1=.520^{*}$ & $\mathrm{P} 1=.000 *$ & $\mathrm{P} 1=.349$ \\
$\mathrm{P} 2=.100$ & $\mathrm{P} 2=.594$ & .217 & $\mathrm{P} 2=.674$ \\
\hline
\end{tabular}

*p1 comparison between pre-post $2^{\text {nd }}$ day $* 2$ comparison between pre-post $7^{\text {th }}$ day

TABLE (4) Showing comparison between preoperative and postoperative mean and standard deviation of three points summation used for swelling assessment after 2 and 7 days among patients included within both groups and level of significance.

\begin{tabular}{|c|c|c|c|}
\hline & $\begin{array}{c}\text { Control group } \\
(\mathrm{n}=10)\end{array}$ & $\begin{array}{c}\text { Study group } \\
(\mathrm{n}=10)\end{array}$ & $\mathrm{p}$-value \\
\hline Pre & $33.36 \pm 1.218$ & $37.73 \pm 1.99$ & $\mathrm{p}=.065$ \\
\hline Post $2^{\text {nd }}$ & $35.08 \pm 1.058$ & $32.650 \pm 1.55$ & $\mathrm{p}=.001$ \\
\hline${\text { Post } 7^{\text {th }}}^{\text {th }}$ & $33.88 \pm 0.758$ & $34.53 \pm 0.947$ & $\mathrm{p}=.231$ \\
\hline
\end{tabular}

\section{Trismus assessment}

The presence of trismus was analyzed through measuring the inter-incisal distance (IID) at maximum mouth opening before the surgical procedures and evaluated at 24,48 hours and7 days postsurgically with a ruler by $(\mathrm{cm})$.

\section{Preoperative assessment}

In control group, patients showed an average mean of IID (4.2 \pm 0.3$)$, while, in study group, patients showed an average mean of IID $(3.1 \pm 0.2)$ (Table 5). No statistical significanct difference was recorded between both groups regarding to (IID) preoperatively $(\mathrm{P}=0.09)$ (Table 5).

\section{Postoperative assessment}

In control group, patients showed an average mean of IID (4.05 \pm 0.126$)$ after 24 hours compared with an average mean of IID (3.86 \pm 0.134$)$ and (4.21 \pm 0.099$)$ after 2 and 7 days respectively. While, in study group, patients showed an average mean

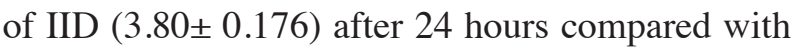

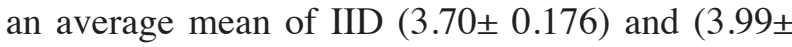
0.218 ) after 2 and 7 days respectively (Table 5). A statistical significant differences were recorded between both groups regarding to (IID) after 24 hours and 2 days $(\mathrm{P}=0.002-0.035$ respectively) (Table 5).

TABLE (5) Showing distribution of pre and postoperative mean and standard deviation of (IID) among patients included within both groups and level of significance.

\begin{tabular}{|c|c|c|c|}
\hline $\begin{array}{c}\text { Group/Time } \\
\text { interval }\end{array}$ & $\begin{array}{c}\text { Control } \\
\text { group }(\mathrm{n}=10)\end{array}$ & $\begin{array}{c}\text { Study group } \\
(\mathrm{n}=10)\end{array}$ & p-value \\
\hline Pre-operative & $4.2 \pm 0.29$ & $4.1 \pm 0.299$ & $=.09^{*}$ \\
\hline 24 hours & $4.05 \pm 0.126$ & $3.80 \pm 0.176$ & $=.002^{*}$ \\
\hline 48 hours & $3.86 \pm 0.134$ & $3.70 \pm 0.176$ & $=.035^{*}$ \\
\hline 7days & $4.21 \pm 0.099$ & $3.99 \pm 0.218$ & $=.01^{*}$ \\
\hline
\end{tabular}




\section{Assessment of surgical time}

The time was assessed from begining until finish the surgical procedures in both groups. In control group, patients showed an average mean $(89.10 \pm 10.92)$ while, in study group, patients showed an average mean (104.10 \pm 13.43$)$ (Table 6). A statistical significant difference was recorded between both groups regarding to time of surgery $(\mathrm{P}=0.013)$ (Table 6).

TABLE (6) Showing mean, standard deviation and level of significance between both groups regarding to time of surgery.

\begin{tabular}{|c|c|c|c|}
\hline $\begin{array}{c}\text { Patient } \\
\text { grouping }\end{array}$ & Mean \pm SD & Min-Max & $\begin{array}{c}\text { Test of sig. } \\
\text { p-value }\end{array}$ \\
\hline Control group & $89.10 \pm 10.92$ & $75-110$ & \multirow{2}{*}{$\mathrm{P}=.013^{*}$} \\
\cline { 1 - 3 } Study group & $104.10 \pm 13.43$ & $80-120$ & \\
\hline
\end{tabular}

Radiographic assessment of bone mineral density (BMD)

All patients in both groups were assessed preoperatively and postoperatively either

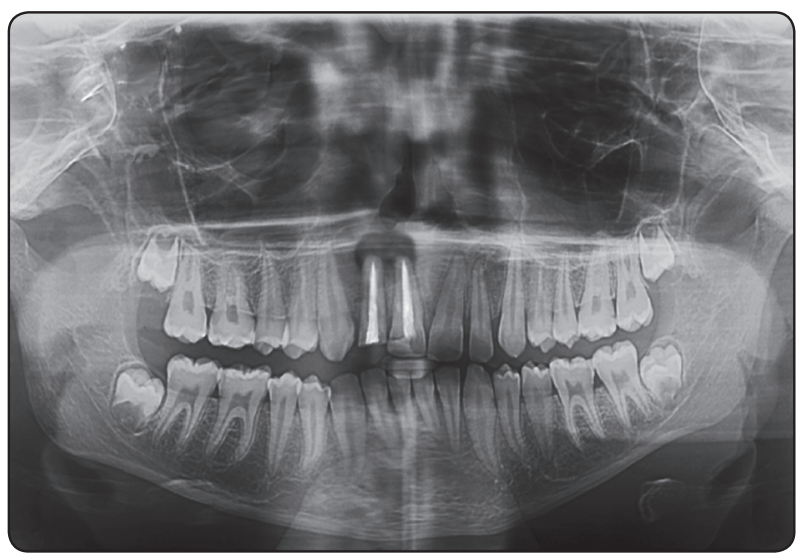

Fig. (3) A photograph showing the immediate postoperative panoramic radiographs in $1^{\text {st }}$ group revealing degree of healing of surgical defect related to upper right central and lateral incisors. immediately, after 6 or 12 months regarding to bone mineral denisty.

\section{Preoperative versus immediate postoperative as- sessment of (BMD)}

Preoperatively, in control group, patients showed an average mean of BMD (36.20 \pm 6.11$)$ while, in study group, patients showed an average mean of BMD (32.40 \pm 4.90$)$ (Table 7). However, immediate postoperative mean value of BMD

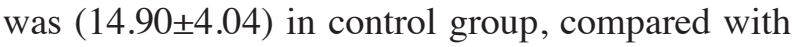
$(13.30 \pm 3.46)$ in study group.(Fig. 3,4). No statistical significant differences were recorded between both groups regarding to bone density either preoperatively or immediate postoperatively $(\mathrm{P}=.142$ 0.354 respectively).

\section{Postoperative assessment of (BMD) after 6 months}

In control group, patients showed an average mean of BMD after 6 months of follow up

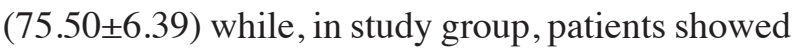
an average mean of BMD $(84 \pm 7.74)$ (Fig. 5,6). A statistical significant difference was recorded between both groups after 6 months postoperatively $(\mathrm{P}=0.015)$ (Table 7).

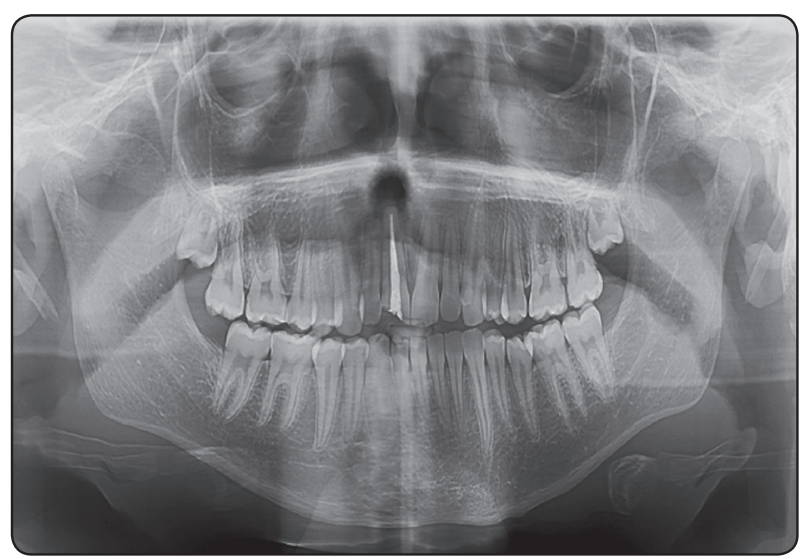

Fig.(4) A photograph showing the immediate postoperative panoramic radiographs in $2^{\text {nd }}$ group revealing degree of healing of surgical defect related to upper right central incisor. 


\section{Postoperative assessment of (BMD) after 12 months}

In control group, patients showed an average mean of BMD after 12 months of follow up (105.20 \pm 33.41$)$ while, in study group, patients showed an average mean of BMD (123.30 \pm 4.57$)$ (Table 7). No statistical significant difference was recorded after 12 months postoperatively between both groups $(\mathrm{P}=.107)$. In both groups, a statistical significant differences were recorded when comparing these values recorded preoperatively versus those recorded immediate postoperatively, at six months and at 12 months postoperatively $(\mathrm{P}=\leq .001)$.

In both groups, a statistical significant differences were recorded when comparing these values recorded immediate postoperatively versus those recorded after six and 12 months postoperatively $(\mathrm{P}=\leq .001)$. Moreover, in both groups, a statistical significant differences were recorded when comparing these values recorded after six months versus those recorded after twelve months postoperatively $(\mathrm{P}=.027, \mathrm{P}=\leq .001$ respectively).

TABLE (7) Showing distribution of pre and postoperative bone mineral density mean and standard deviation values of BMD among patients included within both groups and level of significance.

\begin{tabular}{|c|c|c|c|}
\hline $\begin{array}{c}\text { Group/Time } \\
\text { interval }\end{array}$ & Control group & Study group & $\mathrm{p}$-value \\
\hline Before & $36.20 \pm 6.11$ & $32.40 \pm 4.90$ & $\mathrm{p}=.142$ \\
\hline After & $14.90 \pm 4.04$ & $13.30 \pm 3.46$ & $\mathrm{p}=.354$ \\
\hline 6 month & $75.50 \pm 6.39$ & $84 \pm 7.74$ & $\mathrm{p}=.015^{*}$ \\
\hline 12 month & $105.20 \pm 33.41$ & $123.30 \pm 4.57$ & $\mathrm{p}=.107$ \\
\hline
\end{tabular}

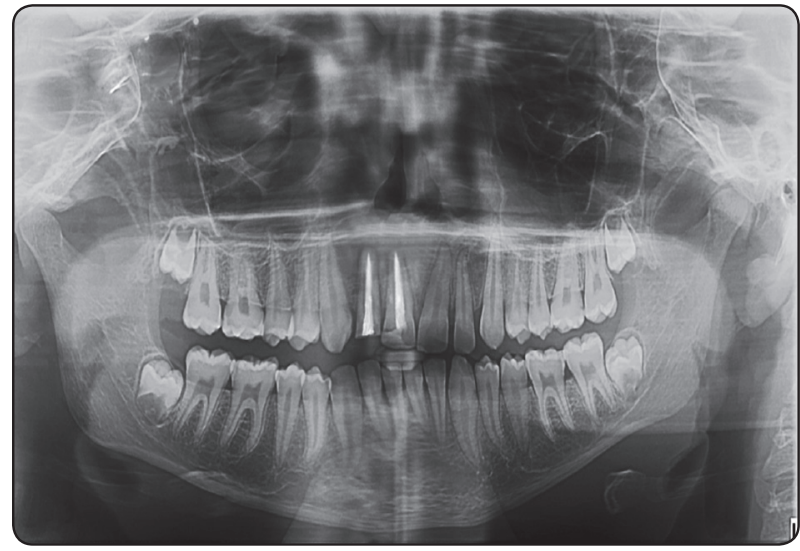

Fig.(5) A photograph showing the postoperative panoramic radiographs in $1^{\text {st }}$ group after six months revealing degree of healing of surgical defect related to upper right central and lateral incisors.

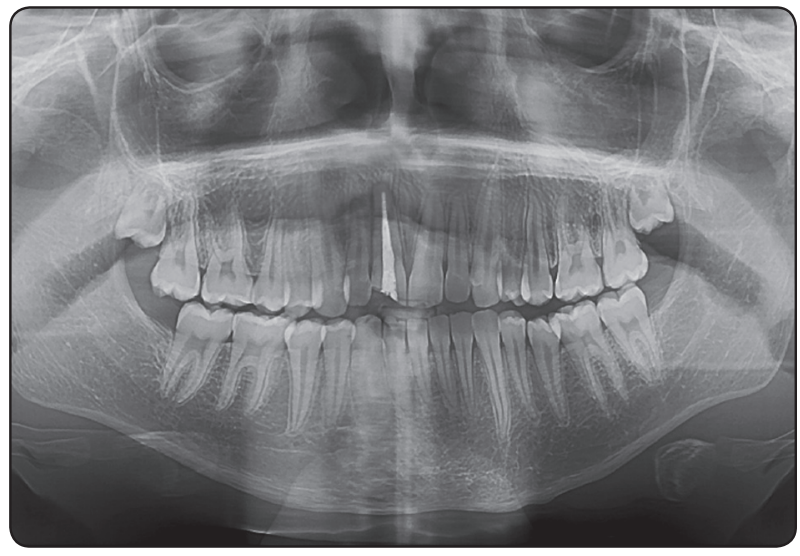

Fig. (6) A photograph showing postoperative panoramic radiographs in $2^{\text {nd }}$ group after six months revealing degree of healing of surgical defect related to upper right central incisor.

\section{DISCUSSION}

For long time prognosis of cyst treatment by conventional enucleation was considered excellent with uncommon recurrence..$^{23}$ The recurrence problem usually related to the biological behavior of the some particular lesions (i.e. keratocysts) and the carefulness of enucleation procedures ${ }^{24-25)}$

The recurrence of the inflammatory cysts (radicular cyst) resulted mainly from incomplete removal of cyst epithelium which consider as a main disadvantage of conventional treatment modality. 
However, piezosurgery tips revealed an important role in enucleation of epithelium remnants of radicular cyst rather than conventional tools particularly in the interdental septa and difficult area. ${ }^{9}$

On the other hand, Crosetti et al; Pavlíková et al., ${ }^{26,27}$ stated that piezosurgery device is considered to be powerful three times rather than conventional ultrasonic of dental office allowing a specific and precise cutting of cortical bone tissues. The oscillation of ultrasonic device frequency occurs as a result of pass of electric current during certain crystal ceramic. ${ }^{26}$ Based on such declaration piezosurgery system was applied in the present study, science it does not cause soft tissues laceration of cyst lining or burns during osteotomy.

Our findings revealed that although, no statistical significant difference between both groups regarding to severity of intraoperative bleeding was recorded $(\mathrm{P}=0.068)$. However, a detectable increase in number of patients who showed mild degree of intraopeartive bleeding were included within study group versus control group. Furthermore, several authors revealed that ultrasonic surgery provides a clearer view of the surgical field than conventional approaches. ${ }^{8,28,29,30}$

The minimal intraoperative bleeding score recorded within study group compared with control group can be attributed to several factors. First, the bleeding tendency associated with rotary instruments which is a reflect to their relative traumatic nature compared with piezosurgery device ${ }^{13,31}$ beside that the cavitation effect created by microvibration of piezosurgery which keep the operational field with a reduced bleeding incidence allowing cystic remnant in the operation site to be easy detected. ${ }^{9}$ Nevertheless, small size of cystic surgical defect $(2-4 \mathrm{~cm})$ for all patients included in this study put a pivotal impact in reduction of incidence of intraoperative bleeding.

Regarding to pain assessment, our findings revealed no statistical significant difference recorded between both groups after 2 days $(\mathrm{P}=.111)$. However, our result showed an initial increase in number of patients who recorded mild degree of postoperative pain severity included within study group. The explantation of minimized degree of pain sensation with piezosurgery in our result can be attributed to the reduction of formation of prostaglandine $E_{2}$, bradykinin and other mediators of pain. Moreover, this type of surgery allows almost atraumatic and minimal invasive surgical procedures that were unlikely with traditional instruments thus sparing pain and complications to the patient..$^{32}$

Our results showed statistical significant differences recorded between both groups at $2^{\text {nd }}$ day postoperatively regarding to the degree of swelling $(\mathrm{P}=.001)$. However, no statistical significant difference was recorded between both groups after 7 days $(\mathrm{P}=.231)$. Our results can be attributed to the main advantage of piezosurgery about its selective cutting ability that recognises the hardness of tissues and works only on mineralised structures with minimal drowback on hard tissues and lack of damage to soft tissues leading subsequently to development of minor postoperative swelling. ${ }^{33}$ Additionally, our findings were in agreement with Kocygiti et al in 2012, ${ }^{9}$ and Pappalardo and Guarnieri in $2013^{32}$ that revealed a lower ratio of swelling with piezosurgery than rotary instruments.

With regard to trismus assessment, our results showed statistical significant difference between both groups after 24 hours, 2 and 7 days ( $\mathrm{P}=0.002$, $0.035,0.01$ reespectively). Such findings can be based on the fact revealing that maximal degree of trismus was liable to occur after first and second days, in parallel with progression of swelling for same time interval of assessment followed by subsequent resolving at $7^{\text {th }}$ day after surgical operation.

In accordance with our results Sortino et al., in 2008; Barone et al. in $2010^{34,35}$ declared that the risk of trismus complications would appear to be lower when piezoelectric bone surgery is used because this technique is less traumatic to the hard and soft tissues. 
Our results showed a statistical significant difference between both groups regarding to time of surgery $(\mathrm{p}=0.013)$. The explanation of long duration of piezosurgery during surgical procedures can be attributed to the nature of such technique which is characterized by pressure application on handpiece that can be varied among practitioner in order to obtain proper adoption leading to reducing cutting efficiency of piezosurgery with subsequent increasing of operation time. However, the piezosurgery devices need only minimal manual pressure $(500 \mathrm{~g})$ for precise and efficient bone cutting, versus conventional drills, but the surgeon apply a greater degree of pressure $(2$ or $3 \mathrm{~kg}){ }^{12}$ Additionally, the microvibrations frequency nature of piezosurgery $(24-29 \mathrm{kHz})$ can be considered as time consuming tools which leads either to prolonged duration of surgery, simulating conventional slow speed handpiece.

Our results were in agreement with Bziet et al in 2007; ${ }^{36}$ Kocygiti et al in 2012; ${ }^{9}$ Pappalardo and Guarnieri in 2013,32 and Yaman and Suer in $2013^{37}$. who stated that ultrasonic bone surgery for enucleating radicular cyst produced a prolonged operation time.

With regard to bone mineral density (BMD), our results showed statistical significant difference recorded between both groups after 6 months (0.015), while at immediate postoperative and after 12 months no statistical significant differences between both groups were recorded $(\mathrm{P}=.354,0.107$ respectively) revealing their early comparable atrumatic cutting nature of piezosurgery against conventional surgical cutting tools.

The explanation of our results can attributed to properties of piezoelectric device which allows minimal amount of bone cutting during surgical operation and provides smooth surface cutting versus the conventional rotary instruments..$^{38,39}$ Additionally, piezoelectric bone surgery seems to be more efficient in the first phases of bone healing. It induces an earlier increase in bone morphogenetic proteins, controls the inflammatory process better, and stimulates remodeling of bone as early as 56 days after treatment. ${ }^{39}$

We believe that piezosurgery application during radicular cyst enucleation is considered to be an acceptable, effective, and promising surgical tool of minimal postoperative complications that was declared from our findings. Unfortunately, the major drawback of piezosurgery is prolonged time consuming than conventional technique that can mainly based on the technique sensitive maneuver varied according to operator experience and device adoption which can not diminish the role of piezosurgery as a novel technique allowing safe and gentile application in both of soft and hard tissues.

\section{CONCLUSION}

Although, piezosurgery can be represented as technique sensitive maneuver affected seriously by several factors either related to operator experience or device adoption by itself. However, the collective findings of this study declared their positive impact on reducing the postoperative sequelae of radicular cyst enucleation compared with conventional treatment modality.

\section{REFERENCE}

1- Ricucci D, Pascon EA, Ford TR, Langeland K. Epithelium and bacteria in periapical lesions. Oral Surg Oral Med Oral Pathol Oral RadiolEndod2004;101:239-249.

2- Santos L.C.S, Vilas Boas DS, Oliveira GQ, Ramos EA, Gurgel CA, Do Santos JN. Histopathological Study of Radicular Cysts Diagnosed in a Brazilian Population. Braz Dent J. 2011; 22(6): 449-454.

3- Sharifian M.J., Kalili M. Odontogenic cysts: A retrospective study of 1227 cases in an Iranian Population from 1987 to 2007. J. Oral Sci. 2011; 53(3):361367.

4- Latoo S, Shah AA, Jan SM, Qadir S, Ahmed I, Purra AR, Malik AH. Radicular Cyst. JK Science. 2009; 11: 187-189.

5- Ribeiro PD, Gonçalves ES, Neto ES, Pacenko MR. Surgical approaches of extensive Periapical cyst. Considerations about Surgical technique. Salusvita, Bauru, 2004; 23(2):317-328. 
6- Stacchi C, Costantinides F, Biasotto M. Relocation of a malpositioned maxillary implant with piezoelectric osteotomies: A case report. Int J Periodontics Restorative Dent 2008; 28:489-495.

7- Miloro M, ed. Peterson's Principles of Oral and Maxillofacial Surgery. 2nd ed. Hamilton, Ontario, Canada: BC Decker, 2004.

8- Vercelotti T, De Paoli S, Nevins M. The piezoelectric bony window osteotomy and sinus membrane elevation: Introduction of a new technique for simplification of the sinus augmentation procedure. Int $\mathrm{J}$ Periodontics Restorative Dent 2001; 21:561-567.

9- Kocyigit ID, Atil F, Alp YE, Tekin U, Tuz HH. Piezosurgery versus conventional surgery in radicular cyst enucleation. $\mathrm{J}$ Craniofac Surg. 2012; 23(6):1805-1808.

10- Eggers G, Klein J, Blank J, Hassfeld S. Piezosurgery: An ultrasound device for cutting bone and its use and limitations in maxillofacial surgery. Br J Oral Maxillofacial Surg 2004; 42,451-453.

11- Ueki K, Nakagawa K, Marukawa K, Yamamoto E. Le Fort I osteotomy using an ultrasonic bone curette to fracture the pterygoid plates. J Craniomaxillofac Surg. 2004; 32(6):381-386.

12- Vercellotti T. Technological characteristics and clinical indications of piezoelectric bone surgery. Minerva Stomatol. 2004;53(5):207-214.

13- Vercelotti T, Nevins ML, Kim DM, Nevins M, Wada K, Schenk RK, Fiorellini JP. Osseous response following respective therapy with piezosurgery. Int $\mathrm{J}$ Periodontics Restorative Dent 2005; 25:543-9.

14- Schaller BJ, Gruber R, Merten HA. Piezoelectirc bone surgery: A revolutionary technique for minimally invasive surgery in cranial base and spinal surgery? Technical note. Neurosurgery 2005; 57:E410.

15- Hoigne DJ, Stubinger S, Von Kaenel O, Shamdasani S, Hasenboehler P. Piezoelectic osteotomy in hand surgery: First experiences with a new technique. BMC Musculoskelet Disord 2006;7:36.

16- Vercellotti T. Essentials in Piezosurgery. Clinical

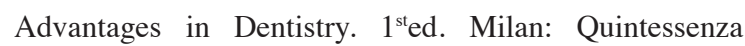
Edizioni; 2009. p65-74, p95-107.

17- Monaco G, Dapril G, Tavernese L, Crinoldesi G, Marchetti C. Mandibular third molae removal in young patients: An evalution of two different flap design. JOral Maxillofac Surge. 2009; 67:15-21.
18- Sriwatanakul K, Kelvie W, Lasagna L, Calimlim JF, Weis OF, Mehta G. Studies with different types of visual analog scales for measurement of pain. Clin Pharmacol Ther 1983;34:234-239.

19- Chopra D, Rehan HS, Mehra P, Kakkar AK. A randomized, double blind, placebo-controlled study comparing the efficacy and safety of paracetamole, serratiopeptidase, ibuprofen and betamethasone using the dental impaction pain model.Int J Oral Maxillofac Surg.2009; 38:350-355.

20- Ustun Y, Erdogan Ö, Esen E, Karsli ED. Comparison of the effects of 2 doses of methyl prednisolone on pain, swelling and trismus after third molar surgery. Oral Surg Oral Med Oral Pathol Oral Radiol Endod. 2003; 96:535-539.

21- Damante J H, Guerra S, Ferreira O J R. Spontaneous resolution of simple bone cysts. Dento maxillofac Radiol. 2002; 31:182-6.

22- Shubhangi Dighe, Revati Shriram. Preprocessing, Segmentation and Matching of Dental Radiographs used in Dental Biometrics. International Journal of Science and Applied Information Technology; ISSN No. 2278 -3083.

23- Marx R, Stern D. Oral and maxillofacial pathology: A rationale for diagnosis and treatment. Chicago: Quintessence Publish-ing; 2003: 573-633.

24- Ellis III E. Surgical management of oral pathologic lesions. In Peterson LJ, Ellis III E, Hupp JR, Tucker MR, editors. Contemporary oral and maxillofacial surgery. 4th ed. St. Louis: Mosby; 2003.p. 481-3.2.

25- Shear M, Speight PM. Cysts of the oral and maxillofacial regions. 4th ed. Oxford: Black-well Munksgaard; 2007: 141-2.

26- Crosetti E, Battiston B, Succo G. Piezosurgery in head and neck oncological and reconstructive surgery: Personal experience on 127 cases. Acta Otorhinolaryngol Ital 29: $1 \mathrm{e} 9,2009$.

27- Pavlíková G, Foltán R, Horká M, Hanzelka T, Borunská H, Sedý J. Piezosurgery in oral and maxillofacial surgery. Int J Oral Maxillofac Surg (2011) 40(5):451-7.

28- Stubinger S, Kuttenberger J, Filippi A, Sader R, Zeilhofer HF. Intraoral piezosurgery: Preliminary results of a new technique. J Oral Maxillofac Surg 2005; 63:1283-7.

29- Schlee M, Steigmann M, Bratu E, Garg AK. Piezosurgery: Basics and possibilities. Implant Dent 2006;15:334-40.

30- Landes CA, Stubinger S, Rieger J, Williger B, Ha TK, Sader R. Critical evaluation of piezoelectric osteotomy in orthognathic surgery: Operative technique, blood loss, time 
requirement, nerve and vessel integrity. J Oral Maxillofac Surg. 2008; 66(4):657-674.

31- Vercellotti T, Pollack AS: A new bone surgery device: Sinus grafting and periodontal surgery. Compend Contin Educ Dent27:319, 2006.

32- Pappalardo S, Guarnieri R. Randomized clinical study comparing piezosurgery and conventional rotatory surgery in mandibular cyst enucleation. Journal of Cranio-MaxilloFacial Surgery (2013) 1-6.

33- Robiony M, Polonu F, Costa F, Vercelotti F, Politi M. Piezoelectric bone cutting in multipiece maxillary osteotomies:TechnicalNote.J Oral MaxillofacSurg 2004; 26:6.

34- Sortino F, Pedullà E, Masoli V. The piezoelectric and rotatory osteotomy technique in impacted third molar surgery: Comparison of postoperative recovery. J Oral Maxillofac Surg. 2008; 66: 2444-2448.
35- Barone A, Marconcini S, Giacomelli L, A randomized clinical evaluation of ultrasound bone surgery versus traditionalrotary instruments in lower third molar extraction. J Oral Maxillofac Surg 2010; 68:330.

36- Beziat JL, Vercellotti T, Gleizal A. What is piezosurgery? Two-years experience in craniomaxillofacial surgery. RevStomatol Chir Maxillofac 2007: 108:101-107.

37- Yaman Z, Suer BT. Piezoelectric surgery in oral and maxillofacial surgery. Annals of Oral \& Maxillofacial Surgery 2013 Feb 01;1(1):5.

38- Samy RN, Krishnamoorthy K, Pensak ML. Use of a noval ultrasonic surgery system for decompression of the facial nerve. Laryngoscope 2007; 117:872.

39- Preti G, Martinasso G, Peirone B. Cytokines and Growth Factors Involved in the Osseointegration of Oral Titanium Implants Positioned Using Piezoelectric Bone Surgery Versus a Drill Technique: A Pilot Studyin Minipigs. J Periodontol. 2007; 78(4):716-22. 